\title{
Optimal care for systemic sclerosis patients: recommendations from a patient-centered and multidisciplinary mixed-method study and working conference
}

\author{
Julia Spierings ${ }^{1}(\mathbb{D})$ Cornelia van den Ende ${ }^{2,3} \cdot$ Rita Schriemer $^{3,4} \cdot$ Lian de Pundert $^{5} \cdot$ Hein Bernelot Moens ${ }^{6}$. \\ Jaap van Laar ${ }^{1}$. Jeska de Vries-Bouwstra ${ }^{7}$. Madelon Vonk ${ }^{3}$
}

Received: 17 September 2018 / Revised: 23 October 2018 / Accepted: 31 October 2018 / Published online: 17 November 2018

(C) The Author(s) 2018

\begin{abstract}
Introduction Systemic sclerosis (SSc) is a chronic autoimmune disease with multiorgan involvement.

Objective Identify preferences and priorities among patients and health care professionals regarding care for SSc patients in The Netherlands. Develop ideas to improve quality of care.

Methods A structured approach was followed to collect information from different perspectives to prepare a working conference. Qualitative and quantitative data from patients $(n=650)$, rheumatologists $(n=167)$, nurses $(n=51)$, and health professionals $(n=85)$ from regional centers and university hospitals were collected. In February 2018, a working conference was organized. Seventy-seven persons (including $10 \mathrm{SSc}$ patients) from different backgrounds discussed the identified themes and survey results. Ideas to improve health care were formulated and prioritized using nominal group technique.

Results Five key themes were identified: (1) shared care and multidisciplinary collaboration, (2) medical data exchange, (3) information for both patients and health care professionals, (4) patient empowerment, and (5) non-pharmacological care. Shared care was the preferred model of care in $49 \%$ of patients and $82 \%$ of physicians. However, current collaboration structures, especially between hospitals, should be improved. Suggestions for improvements were explicitly formulated agreements about referral, clear task division, treatment coordination, and exploration of novel ways to exchange medical records. The creation of a national web-based information hub was highly prioritized.

Conclusion In this mixed-method study, broad-based consensus was achieved and recommendations were developed to improve health care for SSc patients. The approach, recommendations, and challenges summarized in this paper can be of use for health care professionals and other actors involved in patients with rare, chronic, and multisystem conditions.
\end{abstract}

Keywords Consensus methods · Needs assessments · Patient-centered care - Quality improvement - Systemic sclerosis · Teamwork

Electronic supplementary material The online version of this article (https://doi.org/10.1007/s10067-018-4358-x) contains supplementary material, which is available to authorized users.

Julia Spierings

J.Spierings@umcutrecht.nl

1 Department of Rheumatology and Clinical Immunology, University Medical Center Utrecht, Heidelberglaan 100, 3584

CX Utrecht, The Netherlands

2 Department of Rheumatology, Sint Maartenskliniek, Nijmegen, The Netherlands

3 Department of Rheumatology, Radboud University Medical Center, Nijmegen, The Netherlands
4 NVLE, Dutch Patient Organization for Systemic Autoimmune Diseases, Utrecht, The Netherlands

5 Department of Rheumatology, Haga Ziekenhuis, The Hague, The Netherlands

6 Department of Rheumatology, Ziekenhuis Groep Twente, Hengelo, The Netherlands

7 Department of Rheumatology, Leiden University Medical Centre, Leiden, The Netherlands 


\section{Introduction}

Systemic sclerosis ( $\mathrm{SSc}$ ) is a complex disease with multiorgan involvement which can have severe physical and psychosocial impact on daily life $[1,2]$. Providing optimal care for these patients is challenging, as it requires experienced health care professionals, multicenter collaboration, a multidisciplinary approach, and tailored patient education [3]. Although the importance of optimal care, collaboration, and education is broadly recognized, not all patients receive the same high standard of care [4]. A Canadian study showed that only a low percentage of SSc patients received adequate multidisciplinary specialist care [5]. Qualitative studies performed in France and Canada showed the need for improvement of diagnostic process and follow-up organization. Furthermore, there were difficulties in accessing information about SSc and finding experts $[6,7]$.

In The Netherlands, the Arthritis Research and Collaboration Hub (ARCH) foundation was started as a nationwide effort to improve health care for patients with rare systemic autoimmune diseases, including systemic sclerosis (SSc). In February 2018, ARCH organized a working conference about the organization of care in SSc. This paper presents the results of the interviews and surveys with patients and health care providers performed as a preparation for the working conference, summarizes the results of the meeting, and reflects on preferred actions in order to improve the quality of care for patients with SSc.

\section{Methods}

A working group was installed to prepare the working conference. The group was composed of one SSc patient, two health professionals (HPs), and three rheumatologists.

\section{Preparation of the conference: a mixed-method study}

Data collection prior to the working conference comprised interviews and surveys. A structured approach was followed to collect experiences in daily practice, hurdles, and unmet needs from the perspective of patients, rheumatologists, and HPs in The Netherlands. An overview of the process that led to the recommendations is provided in Fig. 1.

Qualitative data were collected in three multicenter focus group interviews. Second, surveys for patients, rheumatologists, nurses, and health professionals were developed to evaluate the identified themes from the interviews in a larger group. The survey included open, multiple choice, and multiresponse questions about current delivery of care, unmet needs, and preferences regarding care, rating of collaboration, multidisciplinary care, medical data exchange, patient empowerment, information supply for patients and health care professionals, and non-pharmacological care. These were assessed on a 5-point Likert scale (1: strongly agree, 2: agree, 3: neither agree nor disagree, 4: disagree, 5: strongly disagree); scoring quality of collaboration and medical data exchange were done with a Likert scale (a slider from 0 to 100). In the multiresponse questions used to prioritize items, participants could choose a maximum of three options, including an option to add a new item.

From the 15th of December 2017 till the 21st of January 2018, 2093 patients treated in 13 different hospitals were invited for the online questionnaire whereas HPs were invited through the participating patients. A total of 350 rheumatologists and 264 nurses from regional and university hospitals were invited by e-mail or approached during the annual meeting of the Dutch Society of Rheumatology at the 28th and 29th of September 2017. For a detailed description of the study methods, see supplementary material; characteristics of the study populations are shown in Tables S1 and S2. The consolidated criteria for reporting qualitative research (COREQ) were followed and reported in Table S4 [8]. The Strengthening the Reporting of Observational Studies in Epidemiology (STROBE) guidelines were followed and reported in Table S5 [9].

\section{Working conference}

\section{Design}

An outline of the results of the interviews, focus groups, and surveys was presented as a starting point in a plenary session. Then, discussions on different themes were held in five small groups (patient education, patient empowerment, nonpharmacological care and two groups on shared care, multidisciplinary collaboration, and medical data exchange), in order to create a constructive action plan that could be used in the ARCH project the upcoming years. Participants were divided in groups by the working group to ensure a diverse composition facilitating a balanced discussion. Nominal group technique (NGT) was used to give every participant the opportunity to share ideas and to reach consensus $[10$, 11]. The NGT process was started with an introduction and explanation about the NGT process. Next, participants were asked to individually and silently generate items and to write these items down on post-its. This was followed by a roundrobin collection of all ideas and recording on a flipchart. Ideas were shortly clarified, discussed, and either categorized, merged, or discarded; if necessary, this was done by voting. In each discussion group, the remaining ideas were discussed in more detail and prioritized by rating. Discussions were led by a member of the ARCH Systemic sclerosis working group and minutes were taken by other ARCH members. At the end of the meeting, the ideas were presented in a plenary session. The day was led by an independent chair and working group 
Fig. 1 Diagram: work streams that led to the recommendations

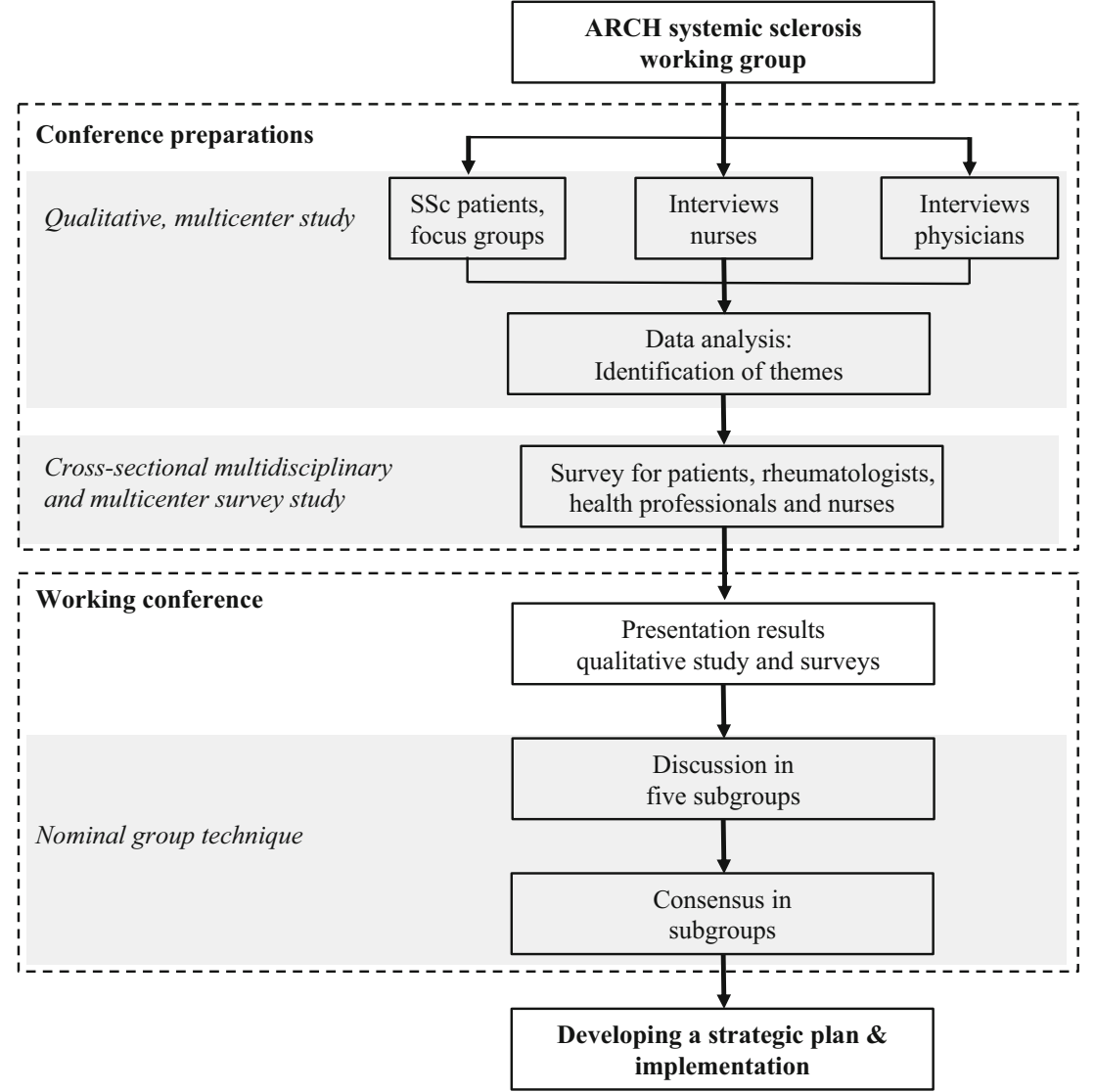

ARCH: Arthritis and Research Collaboration Hub, SSc: Systemic sclerosis sessions were chaired and recorded by the working group. Ideas with consensus and expected challenges were recorded. A summary of the working conference was verified by the participants afterwards.

\section{Setting and participants}

The meeting took place on the 9th of February 2018 in Utrecht, The Netherlands. Patients and health care professionals who participated in the interviews and focus groups were invited to join the conference. Also, invitations were sent to organizations of health care professionals relevant in SSc (cardiology, pulmonology, dermatology, internal medicine, gastroenterology, physical therapy, occupational therapy and nurses, skin therapy, psychology), patient organizations, insurance companies, governmental institutions, funders of scientific research, and other participants in $\mathrm{ARCH}$.

\section{Analysis}

The interviews were analyzed by two independent investigators. Transcripts were read and re-read, using the constant comparative technique. Themes and subthemes were derived from the data by the researchers separately and were discussed until consensus was reached. Descriptive statistics were used to describe characteristics and answering options of respondents from the survey. Means and standard deviations were presented where appropriate. All analyses were performed using SPSS 22.

Results from the group discussions at the conference, which included ideas with consensus and expected challenges, were recorded. A summary of the results from the working conference was made by two independent researchers and was verified by the participants afterwards.

\section{Results}

\section{Participants}

Twenty-three patients participated in the focus group interviews, and 12 rheumatologists and 5 specialized nurses were interviewed individually. Six hundred fifty patients (estimated $31 \%$ of all Dutch SSc patients), 167 rheumatologists (48\% of all Dutch rheumatologists), 51 specialized nurses (21\% of all Dutch specialized nurses), and 85 health professionals completed the survey on the 28th of February. The meeting 
was attended by 77 persons (see Table 1 for details about participants). In Fig. 2, the number of participants is shown at each stage of the study.

\section{Results of the thematic analysis interviews}

Five themes were identified as most important for the quality of care requiring improvement: shared care and multidisciplinary collaboration, medical data exchange between hospitals and health care professionals, patient education, patient empowerment, and non-pharmacological care.

Table 1 Participant working conference

\begin{tabular}{ll}
\hline Participants & $\begin{array}{l}\text { Number } \\
\text { (overlap)* }\end{array}$ \\
\hline SSc patients & $10(6)$ \\
Health care professionals & \\
-Clinical immunologists & 2 \\
-Consultant internal medicine & 1 \\
-Dietitian & 3 \\
-Occupational therapist & 1 \\
-Nephrologist & 1 \\
-Nurses & 9 \\
-Physical therapist & $6(1)$ \\
-Pulmonologists & 2 \\
-Rheumatologists & $12(5)$ \\
-Skin therapist & 1 \\
-Vascular consultant & 1 \\
Organization representatives & \\
-Dutch Society of Rheumatology & 1 \\
-Dutch Society of Health Professionals & 1 \\
-ParkinsonNet & 1 \\
-Scleroderma Patient-centered Intervention Network & 1 \\
Patient organizations & 1 \\
-Dutch Scleroderma Foundation & 1 \\
-Dutch Sjögren's Syndrome Foundation & 1 \\
-Dutch Society for Lupus, APS, Scleroderma and MCTD & \\
-Dutch Vasculitis Foundation & 1 \\
Providers of health care expertise & \\
-IT companies & 1 \\
Funders of scientific research & \\
-Dutch Arthritis Foundation & \\
-Dutch Organization for Health Research and Development & 1 \\
ARCH members & \\
\hline
\end{tabular}

$A R C H$ Arthritis Research and Collaboration Hub, APS antiphospholipid syndrome, IT information technology, MCTD mixed connective tissue disease, SSc systemic sclerosis

*The number of participants that could be categorized in more than one category is reported as "overlap"

\section{Shared care and multidisciplinary collaboration}

In the interviews, patients preferred to be referred to tertiary expert centers earlier in the disease course, but that treatment closer to home should be made possible too. The lack of widely accepted definitions about SSc expertise and centers of expertise came to light. Furthermore, some interviewed rheumatologists working in regional hospitals did not know where to find SSc experienced colleagues. The survey results showed that $49 \%$ of patients $(n=314)$ and $82 \%$ of rheumatologists $(n=133)$ agreed that shared care between highly specialized (tertiary) centers and regional hospitals is the preferred model of care. Current quality of collaboration in shared care was rated by the rheumatologists as just sufficient (score of 65 out of 100 (SD 17)). Fifteen percent $(n=23)$ of rheumatologists and $27 \%(n=171)$ of patients prioritized this as most important hurdle for optimal care (Table 2 shows the top 3 hurdles that hinder optimal care). Unclear division of responsibilities was addressed as an important issue impeding effective collaboration. Forty-four percent of all health care professionals regarded this as the most important obstacle for good quality of care. Seventy-six percent $(n=121)$ of rheumatologists agreed with the statement in the survey that treatment goals of all patients should be discussed and agreed upon in multidisciplinary meeting. However, only $48 \%(n=$ 76) of rheumatologists currently participates in such meetings. Multidisciplinary teamwork was mentioned as an important challenge in $37 \%(n=59)$ of rheumatologists and $11 \%(n=$ 68) of patients. Clear agreements on responsibilities, alignment of treatment strategies, and communication with patients in multidisciplinary collaboration received the highest priority point for improvement among rheumatologists $(45 \%, n=71)$ and patients $(45 \%, n=288)$.

\section{Considerations resulting from the working conference}

In The Netherlands, management of SSc patients is not centralized; patients are treated in regional hospitals or centers of expertise and a relatively small number of patients in both, in the setting of shared care. Participants at the conference stated that shared care enables more patients to receive treatment from experts and shortens overall travel time. Furthermore, this model of care encourages collaboration between centers and increases knowledge sharing. They agreed that shared care should be practiced more in The Netherlands in SSc patients. Networks of hospitals would support shared care and optimal use of experts from several disciplines.

The participants of the conference thought that the initial step should be a consensus on a national level about the minimal requirements of SSc expertise. Next, regional networks need to be formed around these expert centers. The lack of financial incentives could challenge implementing this model 
Fig. 2 Number of participants at each stage of the study

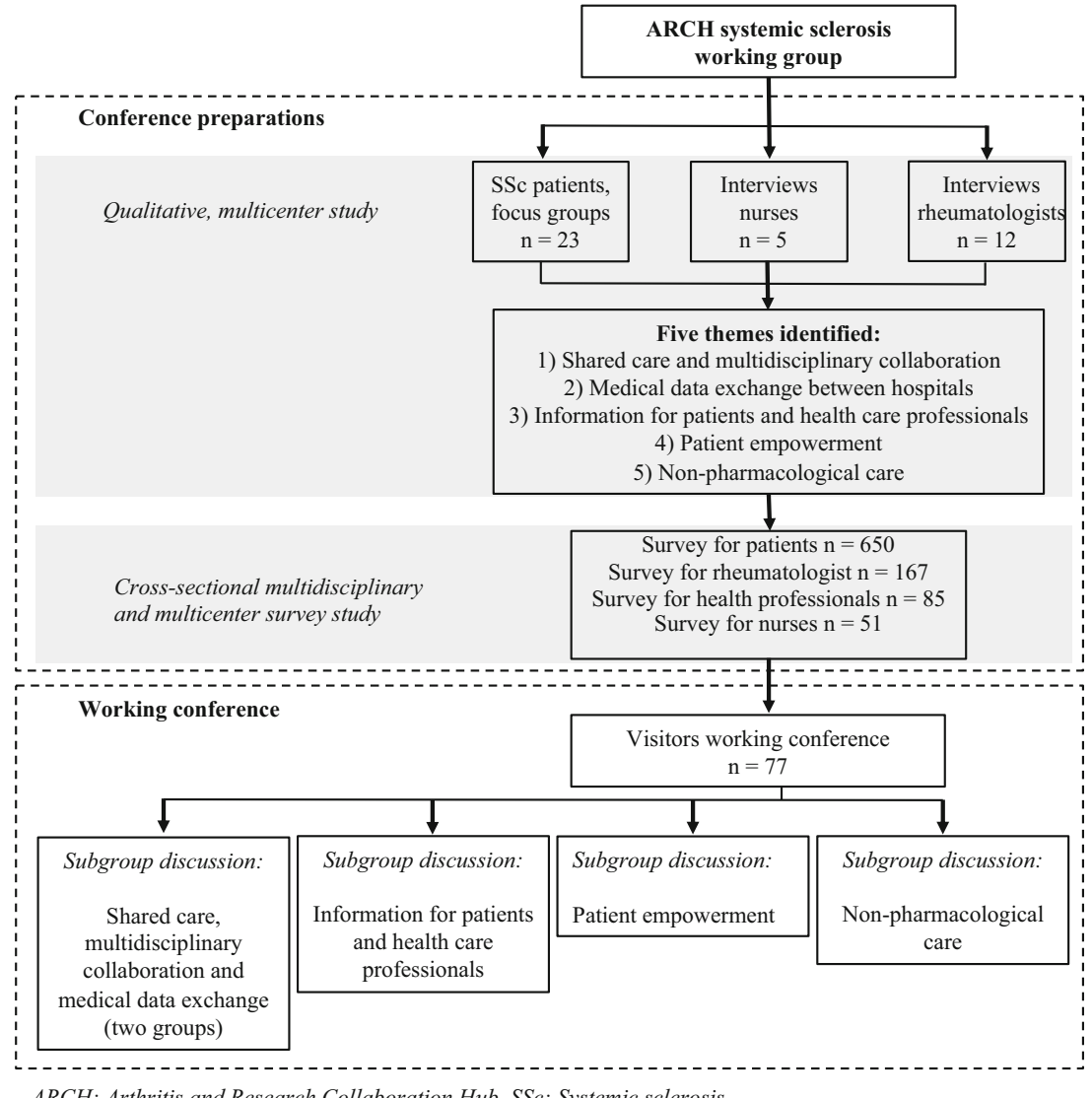

ARCH: Arthritis and Research Collaboration Hub, SSc: Systemic sclerosis of care. Discussions with insurance companies and governmental organizations are therefore of key importance.

\section{Recommendations}

- Clear criteria for expertise of physicians and health care professionals should be made, including minimal caseloads, required education, and composition of multidisciplinary team
- Regional networks should be formed in order to provide high quality of multidisciplinary (shared) care at reasonable travel distance for the patient

\section{Exchange of medical data between hospitals}

Patients treated in shared care reported that they often had to undergo the same diagnostic tests in both centers or had to provide medical data themselves, e.g., blood results. By

Table 2 Priorities in hurdles that hinder optimal care. Comparison of survey results between patients and health care professionals (multiresponse question)

\begin{tabular}{|c|c|c|c|}
\hline & 1 & 2 & 3 \\
\hline $\begin{array}{l}\text { Rheumatologists } \\
\quad(n=158)\end{array}$ & $\begin{array}{l}\text { No clear division of tasks between } \\
\text { hospitals (shared care) }(42 \%)\end{array}$ & $\begin{array}{l}\text { Insufficient collaboration between different } \\
\text { disciplines in one center (37\%) }\end{array}$ & $\begin{array}{l}\text { Insufficient medical data exchange between } \\
\text { hospitals in shared care }(27 \%)\end{array}$ \\
\hline Nurses $(n=49)$ & $\begin{array}{l}\text { Insufficient number of HPs with } \\
\text { knowledge about SSc (45\%) }\end{array}$ & $\begin{array}{l}\text { No clear division of tasks between hospitals } \\
\text { (shared care) }(29 \%)\end{array}$ & $\begin{array}{l}\text { Patient information does not fit the needs } \\
(27 \%)\end{array}$ \\
\hline $\begin{array}{l}\text { Health professionals } \\
\quad(n=85)\end{array}$ & $\begin{array}{l}\text { Insufficient number of HPs with } \\
\text { knowledge about SSc }(44 \%)\end{array}$ & $\begin{array}{l}\text { No clear division of tasks between hospitals } \\
\text { (shared care) }(28 \%)\end{array}$ & $\begin{array}{l}\text { Insufficient collaboration between different } \\
\text { disciplines in one center }(18 \%)\end{array}$ \\
\hline Patients $(n=533)$ & $\begin{array}{l}\text { Insufficient number of HPs with } \\
\text { knowledge about SSc }(40 \%)\end{array}$ & Difficulty to find expert physicians $(27 \%)$ & $\begin{array}{l}\text { Insufficient medical data exchange between } \\
\text { hospitals in shared care }(11 \%)\end{array}$ \\
\hline
\end{tabular}

$H P S$ health professionals, SSc systemic sclerosis 
rheumatologists, exchange of medical data between hospitals was reported as a huge hurdle as well. In the survey, current quality of information exchange was rated as just sufficient by both patients (66 out of 100, SD 24) and health care professionals (57 out of 100, SD 19). Eighty-four percent $(n=132)$ of rheumatologists agreed that support to improve this is needed. An accessible Electronic Patient Record System (EPRS) for all involved physicians was prioritized by $29 \%(n=46)$ of rheumatologists and $23 \%(n=147)$ of patients.

\section{Considerations resulting from the working conference}

In 2011, a national initiative to create a uniform medical record failed because of security and privacy concerns. Therefore, data exchange is still carried out by fax, mail, or phone, which is neither efficient nor secure. Furthermore, when information is missing, patient safety is compromised. At the conference, a personal health record managed and shared by patients, accessible EPRS for physicians in expert centers involved in the treatment of individual patients, and digital data exchange were suggested solutions. A personal health record could be efficient since each patient holds their own medical data. It may even increase patient empowerment. However, the management of personal and often complex information is accompanied with a responsibility that probably only can be handled by a select group of patients. The second idea, enabling full access to the EPRS, is a relatively simple intervention and mostly requires agreements between hospitals and patient consent. During further group discussion, this suggestion was nevertheless rejected, because a completely shared EPRS would probably lead to information overload. A shared care medical record would be most efficient but requires new electronic techniques. These techniques should be integrated in existing EPRSs to prevent additional administrative procedures and medical data on several sites. In order to enable uniform data exchange and facilitate connection between different EPRSs, standard forms should be created.

\section{Recommendations}

- A shared care medical record, accessible for the patient and multidisciplinary team involved, should be developed, containing medical history, treatment goals, disciplines involved, and checklists.

- Standardized forms should be agreed upon and developed for data exchange between health care professionals in shared care.

- Automatic synchronization of treatment goals and changes in treatment between EPRSs of all physicians involved should be made possible.

\section{Information for both patients and health care professionals}

The survey showed that over two thirds of patients and health care professionals ( 70 and $66 \%$ respectively) prioritized a central information hub as their main requirement. More than half of health care professionals and one third of patients desired an online available overview of SSc experts in The Netherlands. An online self-management program was desired by $29 \%$ of patients $(n=184)$, and $36 \%(n=229)$ thought a web-based user-interactive question-answering platform would be an important addition to the current educational propositions. Sixty-eight percent of nurses and $30 \%$ of all HPs preferred an e-learning about SSc.

\section{Considerations resulting from the working conference}

An overarching idea to improve quality on several themes was the creation of a national information platform for all parties. A list of elements for this platform was established. With regard to patient education, differences in individual needs and level of education should be taken into account. Importantly, consensus should be reached on which organization will be responsible for its development and sustainability.

\section{Recommendations}

- Creation of one website with information for both patients and health care professionals. This website should offer:

- Information about experts and clarification of the organization of care in networks of shared care

- Patient education in both written form and animations and pictures

- Self-management program

- Information about ongoing national and international research

- Essential information about SSc for GP in general practitioners, HPs, and medical specialists not specialized in $\mathrm{SSc}$

- The opportunity to join an online network of patients and health care professionals

\section{Patient empowerment}

In the interviews, patients often felt that their role in their treatment and shared decision-making was too small. Also, rheumatologists reported that measures to empower patients are needed. Although $84 \%(n=522)$ of patients in the survey reported that they were involved in treatment decisions, only $63 \%(n=412)$ of patients reported that they actually did receive the care they needed. Eighteen percent $(n=29)$ of 
rheumatologists prioritized the inability to provide appropriate care as most important hurdle. The patient survey showed that symptoms like fatigue ( $46 \%, n=295)$, Raynaud's phenomenon $(31 \%, n=204)$, physical impairment $(30 \%, n=192)$, impaired hand function $(27 \%, n=177)$, and arthralgia $(25 \%, n=$ 163 ) deserve more attention during hospital visits.

\section{Considerations resulting from the working conference}

During the conference, participants agreed that patient empowerment could be improved by helping patients navigating the health care system. A case manager could offer this support. The fulfillment of the role of case manager requires additional training and financial compensation and should be explored further. Secondly, care should be adapted to patients' requirements and preferences. Communication is a key in creating a treatment plan that is patient-centered. Consequently, ways to prepare for doctor's visits were discussed in the groups. The uses of applications, checklists, or peer support were suggested. A possible disadvantage of peer support is misinformation. Another proposal was the implementation of an annual dialogue between physician and patient to evaluate and discuss the treatment process and the quality of care.

\section{Recommendations}

- In order to deliver patient-centered health care in a complex multicenter and multidisciplinary setting, case managers that coordinate teamwork, exchange of data, and patient education are needed.

- Measures to improve consultation preparation should be explored, including a checklist and a peer who will join the patient.

- Annual evaluation with the emphasis on quality of life, daily functioning, expectations, and goals should be implemented.

\section{Non-pharmacological care}

Structural support by a specialized nurse was mentioned in all focus groups as a desirable addition to the current standard of care. Nurses could help patients cope with the daily strains due to functional impairments and offer mental health support. Patients reported that more attention should be paid to non-pharmacological care. The survey revealed that knowledge about where to find HPs with SSc experience is lacking $(39 \%, n=249$, of patients and $25 \%, n=40$, of rheumatologists prioritized this as a hurdle for optimal care).

\section{Considerations resulting from the working conference}

Although SSc has a large impact on physical and psychosocial well-being, little attention is attributed to non-pharmacological care in both clinical practice and research. In the conference, three elements came forward for further exploration in order to improve this: increasing awareness, evidence-based guidelines for non-pharmacological care, and education. These elements were prioritized. Firstly, physicians and patients might not be aware of the possible benefits of non-pharmacological support. By providing information about available treatment options delivered by HPs, more attention would be given to this theme during doctor's visits. The lack of evidence on nonpharmacological interventions could be partly responsible for the neglect of this theme and, importantly, complicates compensation by insurance policies. Thirdly, education of nurses and HPs will increase the quality of care they provide. As HPs working in private practices treat SSc patients infrequently, a network of HPs with SSc expertise is needed to share experience and knowledge.

\section{Recommendations}

- More information about non-pharmacological support for patients and health care professionals should be provided.

- Development of a (national) guideline on nonpharmacological support in SSc is needed.

- Education for HPs to raise awareness, increase knowledge, and create a network should be developed.

\section{Discussion}

In this paper, we report the results of interviews, surveys, and a working conference among a broad panel of stakeholders aiming to identify consensus-based recommendations to improve health care for SSc patients nationwide.

Twelve recommendations were formulated regarding five themes (Fig. 3). The identified themes in SSc care are in line with themes that were shown to be important in other chronic or rare diseases [12, 13]. For instance, patients with neuroendocrine tumors (NET) experienced unmet needs in coordination of care and lack of non-pharmacological care. Interestingly, NET patients in shared care were significantly less satisfied, which was attributed to the larger number of physicians involved. A study in SSc found that the number of disciplines involved was associated with a lower rating in care coordination by patients as well [13]. Our study showed that the model of shared care was preferred by physicians and $50 \%$ of the participating patients. (Multidisciplinary) collaboration between centers however was rated just sufficient. Although we did not investigate the actual performance of teams and the extent and quality of collaboration 
Fig. 3 Recommendations resulting from the working conference
Shared care and multidisciplinary collaboration

- Clear definitions about reference centers and expertise

- Concentration of expertise and a regional infrastructure to provide shared care

Exchange of medical data between hospitals

- A 'shared care record', accessible for the patient and all health care professionals

- A standardized form with regard to the information requires for information exchange

- Automatic synchronization between EPRSs

Information for both patients and health care professionals

- One national information hub for all stakeholders

Patient empowerment

- Coordination of care by case managers

- Patient led annual dialogue about goals and expectations

- Support in preparation of doctors' visit

Non-pharmacological care

- Improved information supply about non-pharmacological support

- Development of a guideline on non-pharmacological support in SSc

- Development of education for health professionals

EPRSs: Electronic Patient Record Systems, SSc: systemic sclerosis in shared care in practice, we think this rating indicates an important impairment in the currently provided care. Furthermore, it reflects the challenges that are faced in multiorgan orphan diseases demanding a large team of experts [3, 14]. In this study, we showed that all stakeholders believe that clear agreements on composition and coordination of multidisciplinary teams could improve the quality of care. Additionally, consensus should be reached on criteria for the appointment of expert centers. Similar efforts were initiated for cystic fibrosis care in the USA [13]. Their strategy also included improvement of leadership of centers and incorporating patients and their families in the improvement effort.

In our study, patients and rheumatologists reported the exchange of medical data as an important hurdle in the collaboration between centers. At the conference, one of the recommendations was a "shared care record" accessible for the patient and health care professionals involved. Interestingly, in this idea and almost all other ideas that were put forwards on this theme, the patient got a prominent and even active role in holding and keeping own medical data. This might increase patient empowerment and fits in the modern health care ambition of patient-centered care [15-18].

An overarching idea resulting from our study was the creation of a national information platform. Other studies already showed that current information provision to SSc patients is insufficient in The Netherlands [19,20]. Accessible education improves clinical parameters and therapeutic adherence [21-23]. Importantly, it also increases empowerment and strengthens patients' position in decision-making processes [24-26].

Another way to stimulate continuous, patient-centered care is the introduction of case managers. Case management focusses on the collaborative process, planning and coordination, and advocacy for options and services to meet an individual's health needs [27]. In patients with chronic conditions, case managers facilitated access to the health care system and the contact with multiple health care providers [28]. Case managers can also be involved in patient education [29].

The strength of this study is the diversity of stakeholders and the large number of patients involved. Although we tried to avoid selection of participants, we realize that only a subgroup of patients and health care professionals completed the survey and attended the conference, implicating selection bias. However, this is the first time that quality of care and unmet needs in SSc have been evaluated in a multidisciplinary group of this size on a nationwide level. In this way, the results from the preparation support the recommendations resulting from the working conference.

\section{Conclusion}

This study achieved consensus and developed recommendations to improve quality of care in patients with SSc in the Dutch health care system. The most fundamental recommendations concern the implementation of shared care, development of efficient system to exchange medical data, and creation of one hub to educate patients, physicians, and HPs. To our knowledge, this is the first time such a multidisciplinary meeting was held with regard to SSc care. Our experiences, approach, and results could therefore be of use for policymakers, health insurance companies, and other stakeholders in The Netherlands and other countries that are involved in the care of patients with rare and multisystem conditions.

Acknowledgements The authors would like to thank C.W.Y. Appels, R. Bakker, S. Bazen, F. Bender, H. Berkers, A.E. van der Bijl, E.W.F. Blaas, 
F. Bonte-Mineur, H. Boerhof, G.W.M. Boerrigter, R. Bos, W.J.W. Bos, C. Bruggink, P.D.M. de Buck, E. van de Burgt, F.S. Catarinella, S. Denktaş, M. Derksen, T. Dhondai, M. Eimers, R.J. Goekoop, E. van Gorp, L.D.M. Gossens, A. Groenendaal-Boender, R. van der Heijden, M.J. Herenius, J. Hofman, J. Huizer, M. Hulsinga, B. Jilderda, R. Jonkers, S.J. de Jong, C.G.M. Kallenberg, M.A.E. de Kanter, M. van Klei, H. Knaapen-Hans, H. Knaken, I. Koopmans, P. Krop, L. Kwakkenbos, R. Langenhuijsen, S. Leroux, I.C. Lether, M. Limper, M. Lohr, L. van Mourik, D.J. Mulder, A. Muns, S. Otter, S Persijn, W.F. Peter, J. Potjewijd, B. Rave, H. de Ruiter, C.G. Schoemaker, T.H.M. Schoonbrood, A.A. Schouffoer, M. Soeters, A.J. Stel, J. Stocker, Y.K.O. Teng, E. Ton, A. van Veen, S. Verhaar, P.M.J. Verhoeven, E. Voogt, M. Voortman, Y. de Vries, A.E. Voskuyl, and J.E.M. WijbransRoodbergen for attending the working conference. They would like to thank the Dutch Society for Lupus, APS, Scleroderma and MCTD for the collaboration. They acknowledge the Dutch Arthritis Foundation (ReumaNederland) for funding the ARCH initiative.

Funding This work was supported by the Arthritis Research and Collaboration $\mathrm{Hub}(\mathrm{ARCH})$ foundation.

\section{Compliance with ethical standards}

\section{Disclosures None}

Open Access This article is distributed under the terms of the Creative Commons Attribution 4.0 International License (http:// creativecommons.org/licenses/by/4.0/), which permits unrestricted use, distribution, and reproduction in any medium, provided you give appropriate credit to the original author(s) and the source, provide a link to the Creative Commons license, and indicate if changes were made.

\section{References}

1. Cinar FI, Unver V, Yilmaz S, Cinar M, Yilmaz F, Simsek I, Erdem H, Pay S, Dinc A (2011) Living with scleroderma: patients' perspectives, a phenomenological study. Rheumatol Int 32(11):3573-3579

2. Nakayama A, Tunnicliffe DJ, Thakkar V, Singh-Grewal D, O'Neill S, Craig JC et al (2016) Patients' perspectives and experiences living with systemic sclerosis: a systematic review and thematic synthesis of qualitative studies. J Rheumatol 43(7):1363-1375

3. Wagner Eh ABT, Con Korff M (1996) Organizing care for patients with chronic illness. Milbank Q 74(4):511-544

4. Harding S, Khimdas S, Bonner A, Baron M, Pope J (2012) Best practices in scleroderma: an analysis of practice variability in SSc centres within the Canadian Scleroderma Research Group (CSRG). Clin Exp Rheumatol 30(2 Suppl 71):S38-S43

5. Johnson SR, Carette S, Dunne JV (2006) Scleroderma: health services utilization from patients' perspective. J Rheumatol 33(6): 1123-1127

6. Mouthon L, Alami S, Boisard AS, Chaigne B, Hachulla E, Poiraudeau S (2017) Patients' views and needs about systemic sclerosis and its management: a qualitative interview study. BMC Musculoskelet Disord 18(1):230

7. Milette K, Thombs BD, Maiorino K, Nielson WR, Korner A, Pelaez S (2018) Challenges and strategies for coping with scleroderma: implications for a scleroderma-specific self-management program. Disabil Rehabil:1-10

8. Tong A, Sainsbury P, Craig J (2007) Consolidated criteria for reporting qualitative research (COREQ): a 32-item checklist for interviews and focus groups. Int J Qual Health Care 19(6):349-357

9. von Elm E, Altman DG, Egger M, Pocock SJ, Gotzsche PC, Vandenbroucke JP (2007) The Strengthening the Reporting of Observational Studies in Epidemiology (STROBE) statement: guidelines for reporting observational studies. Lancet 370(9596): $1453-1457$

10. Delbecq ALVGA (1971) A group process model for problem identification and program planning. J Appl Behav Sci 7(4):466-491

11. Delbecq ALVGA, Gustafson DH (1975) Group techniques for program planning: a guide to nominal group and Delphi processes. Scott Foresman Company, Glenview

12. Beesley VL, Burge M, Dumbrava M, Callum J, Neale RE, Wyld DK (2018) Perceptions of care and patient-reported outcomes in people living with neuroendocrine tumours. Support Care Cancer 26:3153-3161

13. Mogayzel, Dunitz, Marrow (2014) Improving chronic care delivery and outcomes: the impact of the cystic fibrosis Care Center Network. BMJ Qual Saf 23:i3-i8

14. Epping-Jordan JE, Pruitt SD, Bengoa R, Wagner EH (2004) Improving the quality of health care for chronic conditions. Qual Saf Health Care 13(4):299-305

15. Willems LM, Kwakkenbos L, Bode C, van den Hoogen FH, van den Ende CH (2013) Health care use and patients' perceptions on quality of care in systemic sclerosis. Clin Exp Rheumatol 31(2 Suppl 76):64-70

16. Bosch M, Faber MJ, Cruijsberg J, Voerman GE, Letherman S, Grol RP et al (2009) Review article: effectiveness of patient care teams and the role of clinical expertise and coordination: a literature review. Med Care Res Rev 66:5D-35S

17. Richards T (2018) Bring outpatients into the 21st century. BMJ 361(k2472)

18. Taylor J, Rayner H, Smith S (2013) Writing letters to patients. Br J Renal Med 18(1) Supplement P21

19. Schouffoer AA, Zirkzee EJ, Henquet SM, Caljouw MA, SteupBeekman GM, van Laar JM et al (2011) Needs and preferences regarding health care delivery as perceived by patients with systemic sclerosis. Clin Rheumatol 30(6):815-824

20. Schouffoer A, Ndosi ME, Vliet Vlieland TP, Meesters JJ (2015) The educational needs of people with systemic sclerosis: a crosssectional study using the Dutch version of the Educational Needs Assessment Tool (D-ENAT). Rheumatol Int 36(2):289-294

21. Essien O, Otu A, Umoh V, Enang O, Hicks JP, Walley J (2017) Intensive patient education improves glycaemic control in diabetes compared to conventional education: a randomised controlled trial in a Nigerian tertiary care hospital. PLoS One 12(1):e0168835

22. Stenberg U, Haaland-Overby M, Fredriksen K, Westermann KF, Kvisvik T (2016) A scoping review of the literature on benefits and challenges of participating in patient education programs aimed at promoting self-management for people living with chronic illness. Couns 99(11):1759-1771

23. Twigg MJ, Bhattacharya D, Clark A, Patel R, Rogers H, Whiteside H, Yaqoob M, Wright DJ (2016) What do patients need to know? A study to assess patients' satisfaction with information about medicines. Int J Pharm Pract 24(4):229-236

24. Voshaar MJ, Nota I, van de Laar MA, van den Bemt BJ (2015) Patient-centred care in established rheumatoid arthritis. Best Pract Res Clin Rheumatol 29(4-5):643-663

25. Coulter A, Entwistle VA, Eccles A, Ryan S, Shepperd S, Perera R (2015) Personalised care planning for adults with chronic or longterm health conditions. Cochrane Database Syst Rev (3):Cd010523

26. Gionfriddo MR, Leppin AL, Brito JP, Leblanc A, Boehmer KR, Morris MA et al (2014) A systematic review of shared decision making interventions in chronic conditions: a review protocol. Syst Rev 3:38

27. Glettler E, Leen M. (1996) The advanced practice nurse as case manager. Journal of Case Management 5(3):121-126

28. Joo JY, Liu MF (2018) Experiences of case management with chronic illnesses: a qualitative systematic review. Int Nurs Rev 65(1):102-113

29. Sandberg M, Jakobsson U, Midlov P, Kristensson J (2014) Case management for frail older people - a qualitative study of receivers' and providers' experiences of a complex intervention. BMC Health Serv Res 14:14 